\title{
The Use of High Low Architecture in the Creation of Alternative Construction Elements
}

\section{SIGRADI2018 TECHNOPOLITICAS \\ xxii congresso da sociedade iberoamericana de gráfica digital 22th conference of the iberoamerican society of digital graphics 07|08|09|novembro|2018 iau usp | são carlos | sp br}

\author{
Lucas Duarte Martins \\ UFSJ | Brazil | duarte_lucas@msn.com \\ Marina Ferreira Borges \\ UFMG | Brazil | marinafborges@gmail.com
}

\begin{abstract}
This study presents an investigation on how the use of digital tools in the fields of architecture and engineering can help establish a connection between the architectural projects developed within Universities and what is produced by the construction industry, consolidating a critical design process that reflects on the use of current technologies. To do so, it will be necessary to employ knowledge gathered from the intersecting areas of architecture, computation and engineering to rethink the use of common materials directing it towards a non-specialized workforce, a relationship that can be defined as high-low architecture.
\end{abstract}

Keywords: High-Low Architecture; Concrete block; Digital tools; Performance-based design; Construction industry.

\section{INTRODUÇÃO}

Este trabalho objetiva investigar como a utilização de tecnologias digitais no campo da arquitetura e engenharia pode contribuir para estabelecer uma conexão entre o que é realizado dentro das Universidades e o que é produzido pela indústria da construção civil, consolidando processos de projeto capazes de refletir criticamente sobre o uso dessas tecnologias.

Procura-se explorar a criação de alternativas a partir de uma releitura do bloco de concreto como componente construtivo, fazendo uso da modelagem digital como ferramenta "para simular desempenho, incorporando ao projeto análise, conhecimento sobre o material e parâmetros de produção" (BORGES;2016). Partindo desta premissa, a pesquisa irá se debruçar sobre a especulação de materiais e técnicas construtivas para a elaboração de elementos e processos que possam ser incorporados pelo mercado, pela indústria e em canteiros de obras. Para isso, serão desenvolvidas fôrmas para produção de módulos construtivos de concreto que combinados desempenhem papel estrutural, de vedação ou ambos, levando em conta as questões de versatilidade de uso e eficiência estrutural incorporadas como parâmetros de avaliação durante o processo de criação para testar sua resistência e adaptabilidade.

Segundo Borges (2016; p. 295), esta experiência nasce como uma tentativa de explorar as "possibilidades trazidas pelas tecnologias digitais emergentes em projeto arquitetônico e produção no canteiro para uma mudança de paradigma no setor da construção civil". A intenção do trabalho é buscar aproximar a produção realizada na Universidade com a realidade dos processos do canteiro, buscando inovar tanto por meio do desenvolvimento de tecnologia de produtos quanto pela contextualização da tecnologia importada para um contexto regional.

Para tal, será necessário mobilizar conhecimentos nas áreas de arquitetura, computação e engenharia a uma mão-de-obra não especializada, relação que pode ser definida como arquitetura high low. Neste caso, o termo high se refere à alta especificidade técnica envolvida na utilização de softwares para modelagem e análise computacionais e o low se refere ao baixo nível de conhecimento prévio necessário de quem utilizará a tecnologia desenvolvida, bem como ao material empregado em sua produção, que deve ser de fácil acesso.

\section{METODOLOGIA DE PROJETO BASEADO EM PERFORMANCE}

A metodologia de "Projeto Baseado em Performance" (Performance-based Design) consiste no desenvolvimento da forma com o estabelecimento de critérios e parâmetros de uso, geometria, economia ou até mesmo, critérios sociais. Para tanto, são desenvolvidos mecanismos de simulação e geração potencializados pelas possibilidades advindas das ferramentas digitais emergentes de projeto e produção (OXMAN;2008).

Para o desenvolvimento do bloco, definiu-se como parâmetros iniciais a sua geometria, buscando uma maior eficiência estrutural, e versatilidade de uso, ou seja, sua aplicação como elemento estrutural ou de vedação com múltiplos arranjos. Como pressuposto inicial para o 
desenho dos blocos, ficou definido que além de satisfazer demandas construtivas a sua geometria deveria proporcionar uma versatilidade de usos e combinações empregando o princípio de coordenação modular. A coordenação modular é aplicada na produção de componentes com dimensões como $09 \mathrm{~cm} \times 19 \mathrm{~cm} \times$ $29 \mathrm{~cm}$, criando uma "folga" de meio centímetro em cada borda totalizando um centímetro nas dimensões em cada eixo, levando em conta a espessura média do rejunte colocado para o assentamento dos. O uso desse sistema na produção dos blocos de concreto ressalta a importância de se considerar os métodos de construção para o desenho do módulo proposto.

A realização deste estudo se deu em três etapas para 0 desenvolvimento dos elementos construtivos:

Etapa 1: Oficinas de experimentações práticas de construção;

Etapa 2: Desenvolvimento de modelo digital e análise computacional de seu desempenho estrutural com o uso de softwares paramétricos e análise de tensões;

Etapa 3: Produção de fôrmas e fabricação e análise dos blocos através de processos experimentais com ensaios de corpo de prova.

Diferentemente do método geralmente empregado para concepção de sistemas estruturais tradicionais em aço, madeira e concreto, empregou-se um procedimnto circular e recursivo desenvolvido especificamente para esta aplicação. O primeiro passo desse método foi utilizar os resultados da otimização topológica pelo plug-in Milipede para definição dos parâmetros da geometria do bloco. Basando-se nos resultados obtidos, deu-se início ao desenho do bloco adaptando sua forma para atender a parâmetros construtivos e espaciais. Os blocos criados foram então submetidos à análise estrutural no software Scan\&Solve, que opera por meio de uma simplificação do método de elementos finitos. Após os testes de performance, iniciou-se a experimentação física com os materiais necessários à fabricação dos blocos e das fôrmas (concreto e chapas metálicas), o que serviu para informar o redesenho de ambos os elementos.

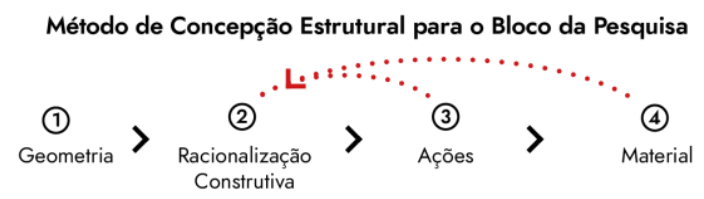

1 - Definição da geometria a partir de otimização topológica de um volume retangular submetido a cargas verticais, permitindo reconhecer um padrão de distribuição do material:

2 - Redesenho da forma gerada pela otimização topológica para potencializar sua aplicabilidade como elemento construtivo;

3 - Definição das ações que incidem sobre o bloco por meio de análise no software Scan\&Solve, empregando propriedades padrão do concreto fornecidas pelo próprio programa e carregamentos previstos pela norma ABNT/NBR 15575:2013, gerando redesenho do bloco;

4 - Investigações acerca do comportamento do concreto influenciado pelo funcionamento da fôrma, gerando redesenho do bloco e da fôrma.

Figura 1: Método de concepção estrutural para o bloco da pesquisa. Fonte: autores.

\section{ETAPA 1: OFICINAS DE EXPERIMENTAÇÕES PRÁTICAS DE CONSTRUÇÃO}

Antes de iniciar os estudos de geometria do bloco, foram realizadas oficinas de experimentações práticas de construção que serviram para facilitar a compreensão de algumas problemáticas construtivas. Foram realizadas três oficinas que serviram para experimentar diferentes formas de prática de construção, tendo estas contribuído para um melhor entendimento e aprofundamento acerca da proposta.

\section{OFICINA 1: ALBORDE}

A primeira oficina realizada foi ministrada por uma integrante do coletivo Alborde durante a XXI Semana de Arquitetura da PUC Minas, que tratou das relações que se dão no canteiro de obras e como arquitetos podem intervir buscando novas relações entre projeto, execução e uso; entre quem projeta, quem constrói e quem utiliza. Alborde é um coletivo equatoriano que realiza projetos empregando processos participativos, trabalhando com orçamentos enxutos, materiais reutilizados e reutilizáveis e geralmente contam com a participação de alunos, proprietários e comunidades organizadas nas etapas de concepção e execução de suas obras. Alguns de seus projetos não partem de um desenho, mas do modo de execução e dos recursos com os quais serão construídos.

Parte do processo consistiu em encontrar pontos em comum entre as diferentes propostas de intervenção para - espaço do canteiro-escola da PUC sem diluir as intenções dos proponentes. Porém, ao anunciar uma proposição, elas deviam estar acompanhadas de duas respostas a duas perguntas fundamentais: $O$ que fazer? $\mathrm{E}$ por quê? Uma vez definidas as prioridades a serem atendidas, os participantes foram subdivididos em grupos responsáveis pela execução das proposições. Para realizá-las, era permitido utilizar apenas materiais, ferramentas e mão-de-obra disponíveis no canteiro; uma prática análoga a situações onde é preciso encontrar soluções improvisadas e tomar decisões rápidas como em canteiros de obras.

Embora o processo tenha sido enriquecedor, os produtos não puderam ser finalizados na oficina devido ao mau tempo. Entretanto, o método de tomada de decisão e ação no canteiro foi importante para a pesquisa pois utiliza uma estratégia que evita reproduzir tecnologias disponíveis, forçando a considerar a escala humana para gerar soluções inovadoras. Essa atividade contribuiu também para experimentar uma mudança de papel de consumidor, que se encontra em uma condição de insatisfação perpétua, para o papel de produtor, que agrega valor ao trabalho ao se reconhecer como sujeito que completa uma ação, já que os participantes eram responsáveis por todas as etapas do projeto. 


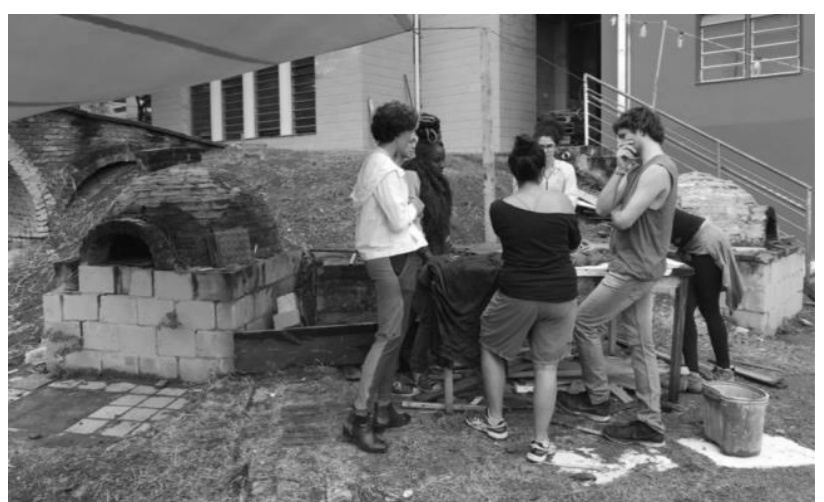

Figura 2: Processo de seleção de materiais para a intervenção durante oficina. Fonte: autores.

\section{OFICINA 2: ATELIÊ AMÉRICAS}

A segunda experimentação foi realizada durante uma oficina ministrada pelo grupo Ateliê Américas com duração de cinco dias, cujo objetivo era explorar a capacidade de combinação do tijolo cerâmico para produção de uma trama sem local ou função definidos, explorando diferentes graus de permeabilidade. O Ateliê Américas é um grupo de pesquisa da UFMG criado recentemente com o intuito de conhecer e reconhecer a arquitetura que vem sendo produzida nos países latinoamericanos.

A oficina teve como proposta a utilização do tijolo uma vez que o país escolhido como objeto de estudo no semestre de realização foi o Paraguai, cuja produção arquitetônica contemporânea tem empregado o tijolo de maneiras excepcionais. Foi solicitado aos participantes que levassem tijolos de diversos tipos e dimensões para a compreensão do comportamento dos blocos em escala real. Os participantes também foram estimulados a exercitar a capacidade de arranjo do tijolo para gerar variados níveis de opacidade e privacidade.

O projeto desenvolvido passou por inúmeras explorações de combinações espaciais e estruturais. Ao final, foi desenvolvido um módulo utilizando uma combinação composta por dois tijolos deslocados num ângulo de 45 graus em relação ao eixo vertical, combinação que gera maior visibilidade em um sentido e maior opacidade e privacidade no outro. Este módulo pode ainda ser espelhado para alternar os lados que desempenham essas funções. Os blocos com orientações diferentes podem também ser combinados em uma mesma parede, que pode ser configurada alternadamente a cada fiada, gerando maior variação de aberturas sem comprometer o encaixe dos blocos. No diagrama abaixo é possível observar a lógica de composição da unidade básica, suas variações e possibilidades de composição.

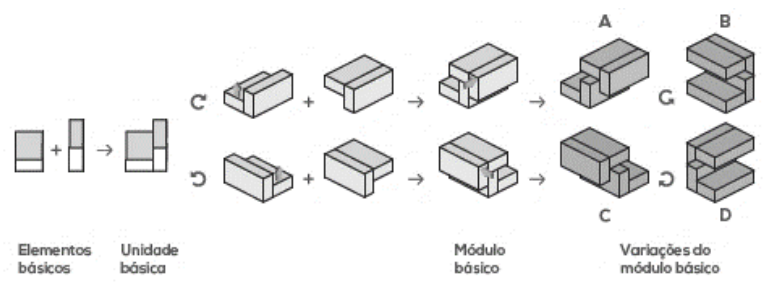

Figura 3: Composição dos módulos básicos. Fonte: autores.
Após o término da oficina, o módulo proposto foi executado em uma olaria. Com a rápida construção deste pequeno modelo, foi possível conferir o efeito espacial da tela utilizando o módulo básico proposto. A experiência de se testar a proposta em escala real com o material real demonstrou a importância da manipulação de um elemento não só digitalmente, mas também fisicamente. O modelo digital permitiu explorar suas diferentes combinações, mas a experimentação com o objeto físico serviu como referência para noções de peso, textura e proporção.

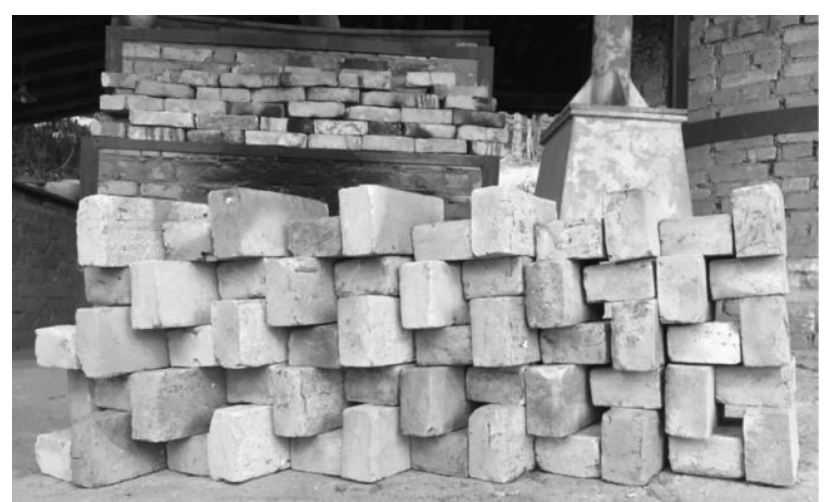

Figura 4: Experimentações na olaria. Fonte: autores.

Esta oficina contribui para experimentar a versatilidade do bloco maciço, ao qual geralmente não atribuímos muito valor para a produção de efeitos extraordinários. Foi possível perceber que um simples elemento apenas pode gerar composições variadas, motivando a investigação sobre as possibilidades que um elemento construtivo pode vir a ter potencializado pela utilização de tecnologias disponíveis no campo da arquitetura e engenharia.

\section{OFICINA 3: SMIA}

O SMiA é um grupo composto por arquitetos de diversas nacionalidades que atuam em seus respectivos países difundindo conhecimento desenvolvido na área de estruturas retráteis, buscando maneiras de aplicá-lo no campo da arquitetura. Nesta oficina foi desenvolvida uma série de objetos tridimensionais para compreender 0 conceito de dualidade em sólidos regulares e o funcionamento de tesouras simétricas e assimétricas, criando estruturas que possuem certos graus de transformação e movimentação.

Os dias iniciavam com breves explicações teóricas sobre o funcionamento das maquetes que seriam desenvolvidas e em seguida os participantes se debruçavam sobre as partes e conexões para confeccionar os modelos. $O$ primeiro modelo criado foi uma estrutura tridimensional, um poliedro que se reconfigura a partir da transformação do centro de suas faces em vértices do outro poliedro. Em seguida, foram realizadas combinações de tesouras simétricas gerando uma malha retrátil que possui diferentes graus de abertura. A terceira maquete foi uma estrutura sinclástica (estrutura cujas linhas de curvatura são definidas pelo mesmo centro de gravidade) construída a partir da combinação de tesouras assimétricas, agrupadas de maneira a permitir um ângulo de curvatura ao ser expandida. 
A experiência com a confecção de estruturas retráteis serviu para a agregar conhecimento sobre o comportamento de estruturas com dimensões variáveis, sobre métodos de conexão e combinação não lineares e conjugação de elementos atuando sob diferentes tipos de forças, como tração e compressão. A absorção desses conceitos e modos de funcionamento pode contribuir na elaboração tanto dos módulos construtivos quanto das formas, estimulando a exploração de modelos reconfiguráveis e adaptáveis.

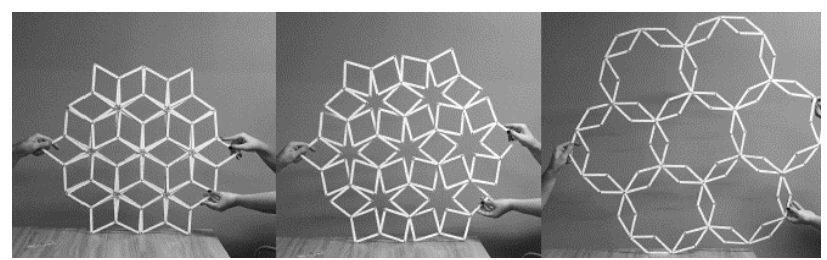

Figura 5: Polígono retrátil. Fonte: autores.

\section{ETAPA 2: DESENVOLVIMENTO DO MODELO DIGITAL E ANÁLISE DO DESEMPENHO ESTRUTURAL \\ DESENVOLVIMENTO DO MODELO DIGITAL}

Para a definição dos parâmetros geométricos do bloco, realizou-se um processo inicial de geração da forma (form finding) baseado na eficiência do material empregando o recurso de otimização topológica pelo plug-in Milipede. O processo de otimização topológica consiste em encontrar a mínima quantidade de material necessária para suportar determinada solicitação de carga. Dada uma quantidade de apoios em uma determinada área sob um carregamento específico, o software se encarrega de eliminar todo material que não contribui para a sustentação do elemento, restando apenas as linhas de força responsáveis pela manutenção de seu equilíbrio interno e por transmitir a carga recebida aos apoios.

Ao contrário do processo de otimização da forma que consiste em um aprimoramento de uma solução convergente/divergente, no processo de geração os critérios de desempenho guiam a geração da forma, incorporando questões estruturais e materiais à geometria ainda nos estágios iniciais de concepção. Desse modo, há uma reversão do paradigma designanálise para a geração baseada no desempenho (BORGES;2015).

Sendo assim, o desenho do bloco partiu de uma análise prévia do comportamento de um prisma retangular sob forças de compressão simples. A partir da otimização topológica de um volume submetido a cargas verticais (ora pontuais ora distribuídas) variando a localização de seus apoios, foi possível reconhecer um padrão de distribuição do material responsável por garantir sua estabilidade estrutural.
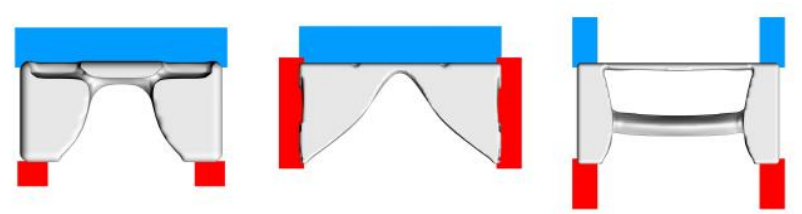

Figura 6: Resultados da otimização topológica no eixo z (vertical). Fonte: autores.
É possível perceber uma maior concentração de material nas extremidades e uma redução de sua quantidade na região central do volume. A partir da identificação desse padrão, os resultados obtidos serviram como referência para o desenho dos blocos, para então serem submetidos à análise de elementos finitos.

Diferentemente do intuito inicial da proposta, que era desenvolver apenas um bloco, o estudo prosseguiu investigando o desempenho de quatro blocos diferentes para comparar as suas respectivas performances, tanto em análise pelo software quanto nos ensaios experimentais.
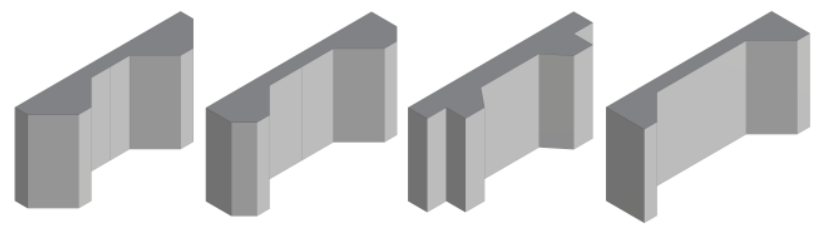

Figura 7: Blocos tipo A, B, C e D, respectivamente. Fonte: autores.

\section{ANÁLISE DO DESEMPENHO ESTRUTURAL}

A partir das geometrias iniciais, foram feitos testes computacionais de performance estrutural utilizando o plug-in Scan\&Solve para Rhinoceros. Esta ferramenta executa análise estrutural por meio da criação de um modelo simplificado de uma malha de elementos finitos (BORGES,2016). A vantagem desta ferramenta para a investigação pretendida foi o fato de exigir pouco conhecimento prévio em sistemas estruturais ou malha por elementos finitos, o que a torna uma ferramenta acessível para o uso de arquitetos e designers.

O método de análise empregado permitiu visualizar as transformações resultantes da aplicação das cargas nos blocos como as tensões, deformações e deslocamentos. Dessa maneira, foi possível iniciar um processo de análise iterativo, permitindo explorar conformações espaciais distintas, e como as alterações de geometria acarretavam um melhor ou pior desempenho estrutural. Foi possível verificar ainda como os elementos se comportariam em diferentes situações de utilização (como peça cheia ou vazada), bastando apenas alterar sua posição em relação ao eixo horizontal e redefinindo seus pontos de apoio e de aplicação da carga.
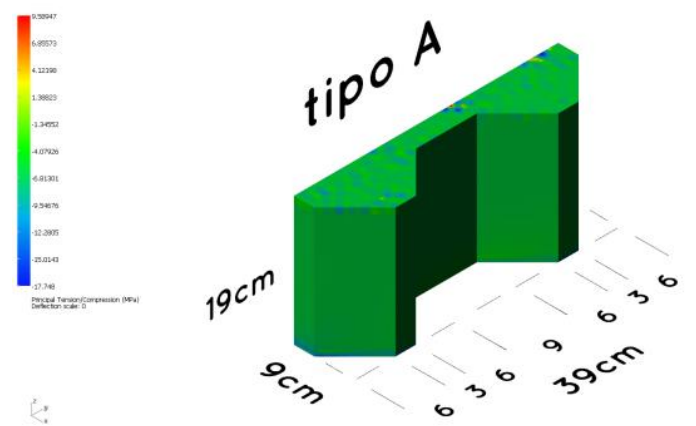

Figura 8: Análise computacional das variações. Fonte: autores.

Embora seja uma ferramenta digital de manuseio relativamente simples, foi necessário realizar uma revisão dos resultados fornecidos pelo programa para determinar como prosseguir com a otimização do desenho. Ao solicitar a ajuda de um engenheiro de estruturas para interpretar os valores obtidos, notou-se uma falta de exatidão nos resultados apresentados pelos critérios de 
falha de Rankine e Coulumb Mohr, que servem para visualizar os pontos onde devem ocorrer concentrações de tensão e o limite de ruptura em materiais frágeis como o concreto. Como o programa utiliza uma simplificação do método de elementos finitos e cria uma malha ao redor do objeto ao invés de subdividir sua geometria original, a precisão da malha criada é comprometida pela impossibilidade de se controlar sua definição geométrica, sendo possível apenas variar a quantidade de pontos.

Verificou-se, então, uma falha do programa quanto à modelagem da malha topológica dos objetos, o que acarretou em uma mudança na utilização dos parâmetros de análise. Os resultados dos critérios de falha estavam sendo empregados devido à sua alta legibilidade gráfica, mas após a verificação de sua baixa confiabilidade nesta aplicação específica decidiu-se interpretar apenas os valores das tensões e deslocamentos resultantes.

Com o intuito avaliar a confiabilidade do programa para os resultados de tensão e deslocamento, realizou-se um teste para analisar os resultados de tensão por meio do cálculo analítico de um volume cilíndrico submetido a forças de compressão simples. Com base nesse teste, foi comprovado que os resultados do programa convergiram para a solução analítica nos resultados das tensões em ZZ (eixo vertical), podendo ser utilizados com confiança.

Todavia, a simulação realizada no software para o teste de compressão dos elementos não apresentou grandes variações com a mudança do formato dos blocos quando utilizados como elemento cheio. Como eles foram elaborados tendo em mente o potencial do concreto em resistir a esforços de compressão e sua fragilidade quando submetido a esforços de tração, as variações no desenho implicaram em mudanças nos valores da análise apenas pela mudança do valor da área de aplicação dos carregamentos, que correspondia ao valor da área de sua face de apoio como peça cheia. Entretanto, a simulação se mostrou eficaz quando os blocos eram dispostos como elemento vazado. Ao alterar a posição da peça e consequentemente seus pontos de apoio, verificou-se o surgimento de forças de tração e então os resultados se tonaram mais relevantes.
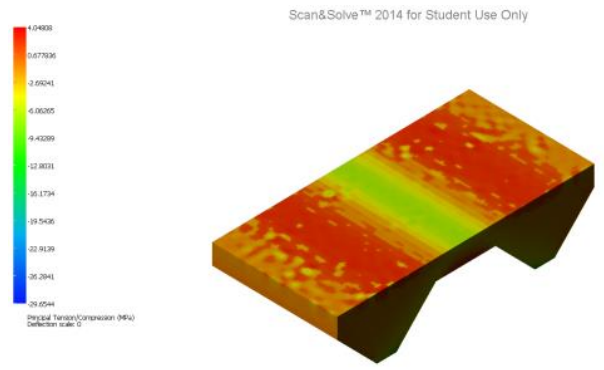

Figura 9: Análise computacional final. Fonte: autores.

\section{ETAPA 3: FABRICAÇÃO DAS FÔRMAS, DOS BLOCOS E ENSAIOS EXPERIMENTAIS}

\section{FABRICAÇÃO DAS FÔRMAS}

Após os testes de performance do bloco por meio de modelo computacional, iniciou-se a $3^{\text {a }}$ etapa que consistiu em elaborar e produzir as fôrmas para fabricação do bloco. Para a produção das fôrmas, pretendia-se inicialmente fabricá-las utilizando impressão digital ou fresadoras $\mathrm{CNC}$, partindo do pressuposto que esta tecnologia pode ser acessível para qualquer usuário sem passar por processos industriais e mercadológicos. Infelizmente, após contatar empresas e universidades que oferecem este tipo de serviço em Belo Horizonte, foi possível perceber que a demanda de produção de objetos de dimensões iguais ou superiores a $20 \mathrm{~cm} x$ $20 \mathrm{~cm} \times 40 \mathrm{~cm}$ é difícil de ser atendida com as máquinas disponíveis atualmente. Além do tempo de produção demasiado longo necessário para a produção de protótipos, estas alternativas se tornaram inviáveis pelo custo financeiro requerido. Mesmo com a sugestão de produzir protótipos em escalas menores, o custo para produção de pequenos blocos em larga escala também extrapolou o limite de recursos financeiros disponíveis para a realização do trabalho. Sendo assim, concluiu-se que o método de fabricação das fôrmas deveria partir do material a ser utilizado, que deveria apresentar desempenho satisfatório como molde de blocos de concreto e possuir alta capacidade de reutilização.

Após a inviabilidade de produção devido ao tempo e custo requeridos pelas opções de fabricação digital, procurou-se uma serralheria para verificar a possibilidade de produção das fôrmas e qual seria o custo envolvido. O serralheiro validou a utilização de chapas metálicas de $2 \mathrm{~mm}$ de espessura, que foram dobradas e cortadas em equipamento específico após envio do desenho detalhado com as medidas de cada segmento para a serralheria. Após esta etapa que se deu de maneira ágil e econômica, as chapas produzidas passaram então por um processo de solda, que também apresentou boa relação de custo-benefício, resultando na conformação de um molde rígido com fundo. Para o primeiro teste, foram produzidas uma fôrma de cada bloco:

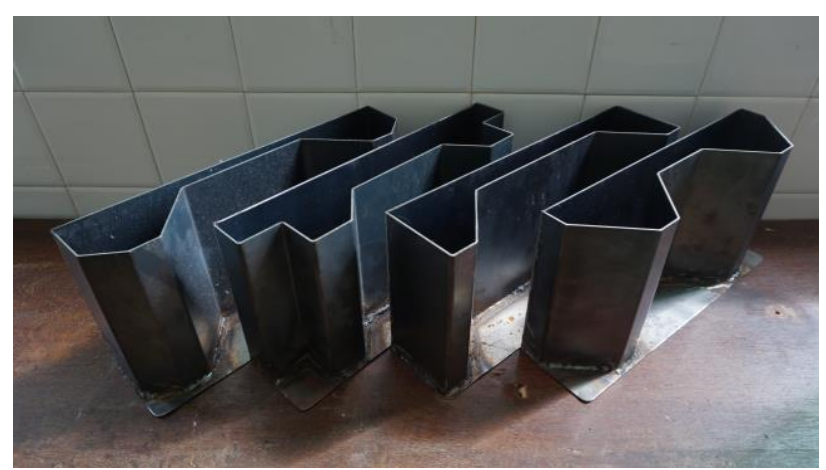

Figura 10: Fôrmas iniciais. Fonte: autores.

Após a confecção das primeiras fôrmas, deu-se início à produção dos blocos com concreto, processo que será detalhado posteriormente.

Uma vez preenchidas, o momento da desforma foi decisivo para avaliação do seu funcionamento. O tipo de molde criado se mostrou ineficiente pois o fundo soldado criou um vácuo de sucção, o que dificultou o desmolde das peças ocasionando sua má-formação. Uma das peças, inclusive, não conseguiu manter sua integridade física por falhas tanto no preenchimento da forma pela argamassa - que não ocorreu corretamente devido ao tamanho dos agregados e ao pouco espaço entre as chapas de aço - quanto no momento do desmolde, não se solidificando o suficiente após o processo de cura, o que resultou em sua ruptura ao ser tocada. 
A solução encontrada para este problema foi criar fôrmas vazadas que pudessem ser desmontáveis e não precisassem ser removidas sendo puxadas para cima, o que poderia causar defeitos nas peças novamente. Utilizaram-se então dobradiças e um porta-cadeados que foram soldados às chapas para evitar interferência nos blocos pela utilização de parafusos. Deste modo, foi possível produzir fôrmas que pudessem ser facilmente esvaziadas sem ameaçar a integridade das peças, como pode ser observado a seguir.

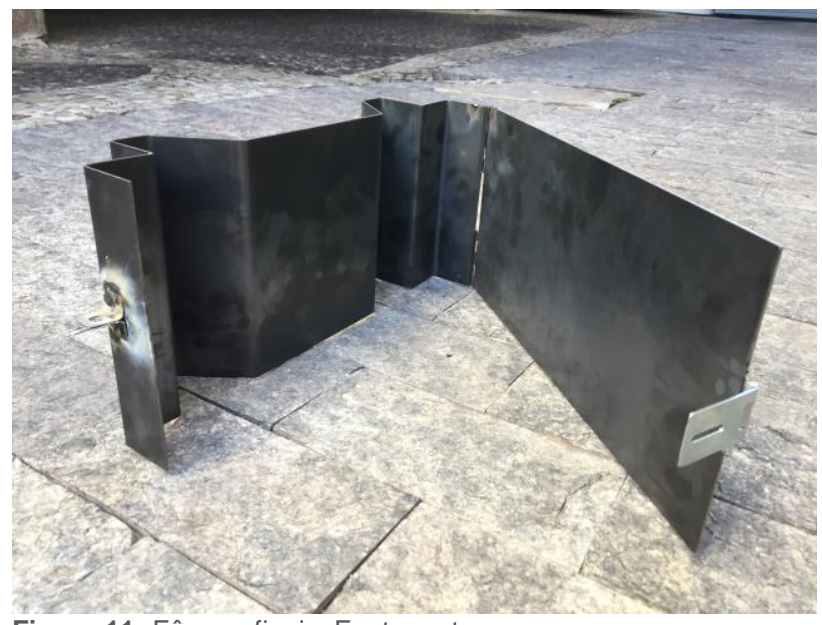

Figura 11: Fôrmas finais. Fonte: autores.

\section{FABRICAÇÃO DOS BLOCOS}

Diante da necessidade de elaborar um traço de concreto e manusear as fôrmas, desencadeou-se um outro estudo sobre qual tipo de traço seria necessário para gerar elementos que pudessem ser desenformados rapidamente e com capacidade de serem submetidos a testes de compressão, o que demandou uma intensa pesquisa sobre quais ingredientes seriam necessários para compor o traço e suas respectivas quantidades. Embora o foco do trabalho seja a criação das fôrmas, este processo foi incrivelmente enriquecedor por promover uma aproximação com a realidade de uso do material.

Existe uma noção errônea de que a elaboração de um traço de concreto seja uma tarefa simples ou de que o concreto seja um material relativamente fácil de ser trabalhado. Após pesquisas, conversas com profissionais que possuem longa experiência prática e fundamentação teórica sobre o assunto e principalmente pela tentativa de realizar um traço de concreto sem o aparato técnico necessário, percebeu-se que é um material cuja produção exige enorme rigor científico em vista de garantir que o produto desempenhe uma performance adequada como demandam as normas reguladoras. Embora a produção de blocos e estruturas de concreto possa ser realizada mesmo sem o controle tecnológico necessário, esta prática apresenta grande risco à integridade das estruturas construídas.

Constatou-se, por meio desta pesquisa, que o melhor tipo de concreto que atenderia ao intuito do trabalho seria o concreto auto adensável, pois dispensaria a utilização de uma mesa vibratória para compactação dos blocos uma vez que sua composição plástica permitiria preencher completamente as fôrmas, criando quinas ativas e garantindo o adensamento de partículas requerido para a consolidação dos blocos. Porém, por sua elaboração ser de extrema especificidade técnica e não haver recursos disponíveis para sua produção no momento do trabalho, decidiu-se empregar um concreto seco e tentar compactá-lo manualmente, ciente das implicações que isso poderia trazer ao desempenho dos blocos.

Ainda que o material não tenha sido elaborado sob um controle tecnológico rigoroso, os blocos foram fabricados com o intuito de simular o processo de ensaio de compressão simples e aproximar este processo à sucessão das etapas estabelecidas para 0 desenvolvimento deste produto.

A partir de um estudo comparativo da resistência à compressão de blocos de concreto, decidiu-se utilizar um traço com proporção 1:6 (cimento:agregados). Embora este traço exija maior consumo de cimento, os blocos produzidos utilizando esta proporção apresentaram maior resistência à esforços de compressão (PADILHA;2017). A dosagem dos ingredientes pode ser conferida a seguir.

Tabela 1: Traços unitários utilizados na produção do concreto

\begin{tabular}{|c|c|c|c|c|}
\hline \multicolumn{5}{|c|}{ Traço 1:6 (cimento:agregados) } \\
\hline Cimento & $\begin{array}{c}\text { Areia } \\
\text { Fina }\end{array}$ & $\begin{array}{c}\text { Areia } \\
\text { Média }\end{array}$ & $\begin{array}{c}\text { Brita } \\
\text { "0" }\end{array}$ & $\begin{array}{c}\text { Relação } \\
\text { Água/Cimento }\end{array}$ \\
\hline 1 & 3,9 & 1,2 & 0,9 & 0,4 \\
\hline
\end{tabular}

Com base no estudo mencionado anteriormente, decidiuse utilizar o cimento CP V-ARI (Cimento Portland de Alta Resistência Inicial). Como o próprio nome indica, ele foi eleito o mais adequado para a produção de elementos que devessem apresentar uma capacidade de resistência considerável mesmo com poucos dias de cura. Este tipo de cimento é geralmente empregado onde se exige desforma rápida, como na indústria de pré-moldados e concreto protendido pré e pós-tensionado.

\section{ENSAIOS EXPERIMENTAIS}

Apôs os testes de fabricação com as fôrmas, sentiu-se a necessidade de realizar ensaios laboratoriais para compreender como atestar fisicamente a resistência dos elementos modelados, já que as peças podem apresentar um comportamento diferente devido às características variáveis da composição do material. Infelizmente, não foi possível realizar o ensaio de resistência dos prismas, que consiste em uma junção de dois blocos unidos por uma camada de argamassa, e da resistência de uma parede como exige a norma ABNT/NBR 15575:2013. Para tal, seria necessário que os blocos produzidos fossem submetidos a um tempo de cura de 28 dias e então fosse aplicada a argamassa, que demandaria mais 28 dias para que pudesse ser testada, excedendo o prazo de conclusão do trabalho. Mesmo não tendo sido realizados sob condições ideais, os ensaios serviram para analisar o desempenho dos blocos e como um aprendizado sobre as demandas do método de ensaio.

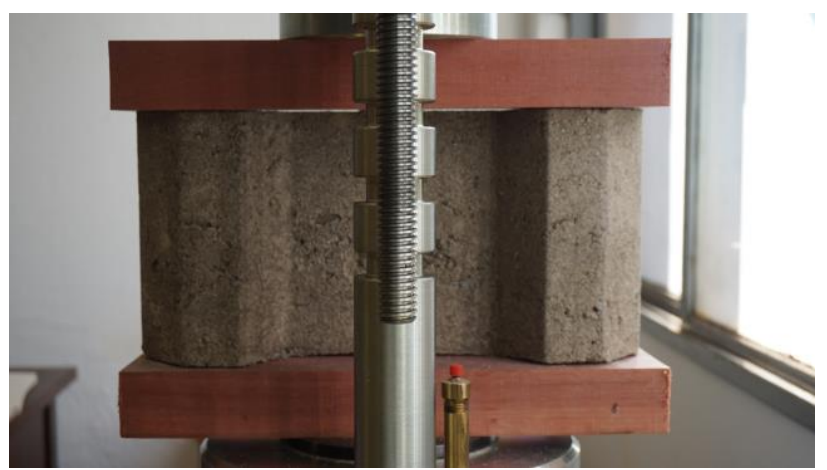

Figura 12: Bloco A em ensaio de compressão. Fonte: autores. 
Os resultados do experimento se mostraram satisfatórios pois foi possível fazer uma leitura clara sobre o funcionamento real dos blocos quando submetidos à esforços de compressão simples. Verificou-se o rompimento dos volumes nas áreas da superfície onde havia maior concentração de material, ou seja, nas "pernas" dos blocos. Enquanto ainda estavam na máquina, as únicas deformações sofridas visíveis estavam localizadas em áreas onde a seção transversal era mais robusta. Não foi possível realizar o ensaio no bloco C pois ocorreu uma falha no momento de desforma que comprometeu gravemente sua conformação.

Tabela 2: Resultados dos Ensaios de Resistência à Compressão

\begin{tabular}{|c|c|}
\hline Tipo de Bloco & Resultado \\
\hline A & $16,28 \mathrm{MPa}$ \\
\hline B & $16,67 \mathrm{MPa}$ \\
\hline D & $25,39 \mathrm{MPa}$ \\
\hline Média & $19,44 \mathrm{MPa}$ \\
\hline
\end{tabular}

\section{RESULTADOS}

A partir da construção de um método para a criação de blocos de concreto, desenvolveu-se um processo projetual crítico acerca da utilização das ferramentas digitais disponíveis no campo da arquitetura e engenharia como instrumento de potencialização da competência propositiva, ampliando a rede de conexões entre os diversos agentes do setor da construção civil. Este exercício promoveu questionamentos não somente acerca do modo de funcionamento dos softwares utilizados, mas principalmente com relação ao motivo pelo qual são empregados, incentivando um raciocínio sobre qual ocasião justifica o seu uso e em qual momento eles se mostram mais vantajosos. Foi importante reconhecer seus potenciais e limitações de acordo com a assimilação do usuário e compreender onde a sua manipulação deve estar situada ao longo do processo, reconhecendo sua influência sobre o que está sendo produzido. Desse modo, busca-se evitar que esses instrumentos projetuais operem como limitadores do processo criativo ou da capacidade propositiva para que auxiliem, de fato, na ampliação de um repertório projetual.

Durante este ciclo, ocorreu uma pequena incursão na área da engenharia dando início a um curto porém relevante diálogo com essa disciplina devido ao fato deste estudo adentrar uma área que demanda um conhecimento de alto nível de especificidade para a resolução do problema proposto. Vale frisar que essa interlocução apenas se tornou possível graças à disposição de profissionais para fornecer informações, ensinamentos e críticas construtivas que demonstraram possuir um valor imensurável para o crescimento profissional do autor.

Esses contatos foram imprescindíveis para realçar a necessidade de se conseguir discernir as contribuições produtivas para o andamento da pesquisa, tornando possível percorrer diversas áreas da ciência sem perder o controle preciso para direcionar os esforços e alcançar os objetivos estabelecidos.

Além de ter expandido os conhecimentos almejados nas áreas de computação, análise estrutural e práticas construtivas, foi possível aproveitar a experiência adquirida à resolução de problemas e criação de alternativas reais, o que demandou a assimilação de processos reais de desenho, fabricação e construção, aproximando teoria à prática, o meio digital ao analógico; ou então, o conhecimento teórico ao estudo incorporado, que se tornou o próprio método de trabalho.

É importante considerar o material produzido como fruto de um processo recursivo que não foi dado como encerrado. Para que se atinja todos os objetivos propostos inicialmente, são necessárias novas etapas iterativas entre (re)estabelecimento de parâmetros, (re)modelagem, análise de desempenho, fabricação de protótipos e ensaios laboratoriais. Assim sendo, fica posto que o elemento que se pretendeu desenvolver demanda mais investigação e exploração de outros métodos que não foram empregados nesse estudo. Pode-se afirmar, portanto, que o trabalho teve como produto final 0 desenho de um processo, e não somente o desenho de um objeto.

\section{DISCUSSÃO}

No trabalho desenvolvido, foi possível compreender relações múltiplas entre processos de projeto e produção. A modelagem física e a preparação para fabricação, produção e montagem anteciparam questões produtivas, construtivas, estimulando a consulta à especialistas e fornecedores reais, buscando a viabilidade de se utilizar maquinário industrial digital no arranjo produtivo.

Para a exploração das novas tecnologias digitais é fundamental criar um diálogo mais próximo com o contexto regional. Esta postura é fundamental para o desenvolvimento de ensino e pesquisa utilizando ferramentas digitais nas universidades do Brasil e na América Latina. $\mathrm{O}$ uso das tecnologias digitais no ensino

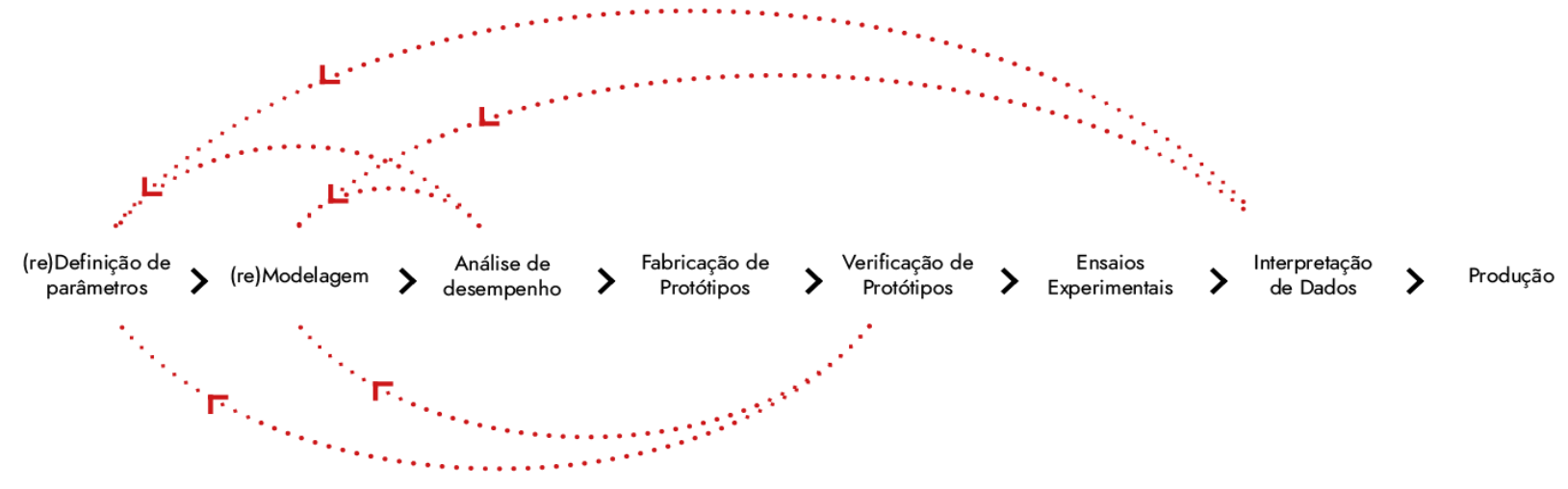

Figura 13: Diagrama do processo recursivo elaborado. Fonte: autores. 
não deve servir apenas para explorar a reconstrução de uma linguagem arquitetônica, mas podem ser utilizadas para desenvolver processos construtivos e pesquisas com materiais, repensando alternativas sustentáveis de produção.

A alvenaria é o elemento construtivo mais comum encontrado nos canteiros de obras brasileiros, devido principalmente a não necessidade de uma mão de obra especializada para utilizá-lo, e, do seu baixo custo. A reflexão sobre este elemento construtivo hegemônico utilizando ferramentas digitais propiciou uma reconexão da Universidade com o canteiro de obra (já que foram pensados aspectos construtivos do material e sua relação com a mão de obra) e com a indústria de materiais e equipamentos (para produção das fôrmas e na investigação da resistência do material). Baseado nas conexões de Pavitt (1984) adaptadas por Borges (2016) para a análise setorial da construção civil, podemos concluir que o uso das ferramentas digitais estimulou no desenvolvimento de uma postura crítica sobre um elemento hegemônico, refletindo não só sobre a lógica do mercado do produto em questão, mas de toda a cadeia de relações entre os agentes da construção civil.

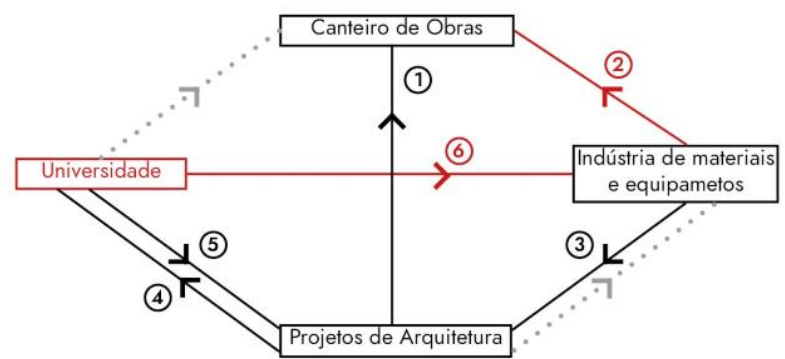

1 - Projetos de arquitetura orientam a construção no canteiro

2 - Fornecimento de materiais e equipamentos para o canteiro, visando a racionalização dos processos

3 - Projetos de arquitetura especificam materiais existentes na indústria

4 - Universidade estuda projetos arquitetônicos

5 - Universidade fornece mão de obra para o mercado

6. Universidade desenvolve componentes para a indústria

Figura 14: O papel proposto pela pesquisa para a arquitetura na cadeia de produção da construção civil baseado nas conexões de Pavitt (1984). Fonte: autores.

\section{AGRADECIMENTOS}

Agradecemos à professora Fernanda Nascimento Corghi e ao professor Mateus Martins, da UFSJ, ao professor Lucas Grilo e ao professor Edgar Carrasco, da UFMG, pelo apoio indispensável para o desenvolvimento do trabalho.

\section{REFERÊNCIAS}

Archdaily. Em foco: Lelé. Janeiro de 2016. Disponível em: <http://www.archdaily.com.br/br/780107/em-foco-lele>

(Acesso em10 Mai 2018. ISSN 0719-8906.
Archdaily. Arena do Morro / Herzog \& de Meuron. 27 Mai 2014. ArchDaily Brasil. (Trad. Delaqua, Victor). Disponível em: $<$ https://www.archdaily.com.br/br/603509/arena-do-morroslash-herzog-and-de-meuron>. Acesso em: 17 Set 2017. ISSN 0719-8906.

Associação Brasileira de Normas Técnicas. (2008). NBR 6136: Blocos Vazados de Concreto Simples para Alvenaria Requisitos. Rio de Janeiro.

Associação Brasileira de Normas Técnicas. (1992). NBR 7184: Determinação da resistência à compressão. Rio de Janeiro.

Associação Brasileira de Normas Técnicas. (1983). NBR 8215: Prisma de Blocos Vazados de Concreto Simples para Alvenaria Estrutural Preparo e Ensaio à Compressão. Rio de Janeiro.

Associação Brasileira de Normas Técnicas. (2011). NBR 12118: Blocos Vazados de Concreto Simples para Alvenaria Métodos de ensaio. Rio de Janeiro.

Associação Brasileira de Normas Técnicas. (2013). NBR 15575: Edificaçõs Habitacionais - Desempenho. Rio de Janeiro.

Borges, M. F. (2016). A Fabricação Digital e o Papel da Arquitetura para uma Mudança de Paradigma TecnoEconômico no Setor da Construção Civil. p. 290-296. In: XX Congreso de la Sociedad Iberoamericana de Gráfica Digital [=Blucher Design Proceedings, v.3 n.1]. São Paulo: Blucher.

Borges, M. F. (2015). Design estrutural baseado em desempenho aplicado ao desenvolvimento de estrutura de torre eólica. Dissertação (Mestrado em Engenharia de Estruturas) - Escola de Engenharia, UFMG. Belo Horizonte.

Braida, Frederico, et al. (Orgs.). (2016). 101 conceitos de arquitetura e urbanismo na era digital. São Paulo: ProBooks.

Oxman, Rivka. (2008). Performance-based Design: Current Practices and Research Issues. International Journal of Architectural Computing vol. 6 - no. 1, pp. 1-17. 6.

Padilha, Stael Amaral; et al. (Orgs.). (2018). Estudo Comparativo da Resistência à Compressão de Blocos de Concreto Produzidos com Diferentes Cimentos e Dosados em Ambiente de Fábrica. REEC - Revista Eletrônica de Engenharia Civil, [S.I.], v. 13, n. 2, maio 2017. ISSN 2179$0612 . \quad$ Disponível em: <https://www.revistas.ufg.br/reec/article/view/46469>. Acesso em: 10 jun. 2018.

Pavitt, K. (1984) Sectoral patterns of technical change: towards a taxonomy and a theory, Research Policy, 13, 343-373.

Plataforma Arquitectura. Carlos Cámara. "Hacia una cultura de software responsable en la arquitectura" 19 jun 2018. Plataforma Arquitectura. Acesso em 20 Jun 2018. <https://www.plataformaarquitectura.cl/cl/896595/hacia-unacultura-de-software-responsable-en-la-arquitectura>. ISSN 0719-8914.

Rebello, Y. (2009) A Concepção Estrutural e a Arquitetura. São Paulo: Zigurate.

Vilaça, Í. (2016). Forma, processo e prática política: experiências críticas e alternativas na arquitetura brasileira. São Paulo: Edições Aurora. 